\title{
Vigilancia epidemiológica para la identificación de casos de infección respiratoria aguda por enterovirus D68 en niños en un hospital de tercer nivel de atención durante 2014-2016
}

\author{
Ana Estela Gamiño-Arroyo ${ }^{1,2 *}$, José Luis Sánchez-Huerta1, Alicia Elhaín de la Garza-López', Israel Parra- \\ Ortega ${ }^{1}$, Noé Escobar-Escamilla ${ }^{3}$,Edgar Mendieta-Condado ${ }^{3}$, Fabiola Garcés-Ayala ${ }^{3}$, Gisela Barrera-Badillo ${ }^{3}$, \\ José Ernesto Ramírez-González ${ }^{3}$, José Alberto Díaz-Quiñonez ${ }^{2,3}$ y Daniela de la Rosa-Zamboni ${ }^{1}$ \\ ${ }^{1}$ Hospital Infantil de México Federico Gómez; ${ }^{2}$ Facultad de Medicina, Universidad Nacional Autónoma de México; ${ }^{3}$ Instituto de Diagnóstico y \\ Referencia Epidemiológicos (InDRE) Dr. Manuel Martínez Báez. Secretaría de Salud, Ciudad de México, México
}

\begin{abstract}
Resumen
Introducción: La reemergencia de las infecciones por Enterovirus D68 (EV-D68) se reportó en los EE.UU. desde agosto-octubre de 2014 (691 casos). En México, un brote se reportó en el Instituto Nacional de Enfermedades Respiratorias (24 casos). Se presentan los resultados de la vigilancia epidemiológica en un hospital pediátrico nacional de tercer nivel para Enterovirus sp. (EV) y otros virus respiratorios. Método: Tras la alerta emitida por la reemergencia del EV-D68 en 2014, la vigilancia epidemiológica - que solo detectaba virus respiratorios mediante PCR en pacientes con enfermedad tipo influenza mediante toma de hisopados nasofaríngeos - se expandió para incluir niños con exacerbación de asma o dificultad respiratoria aguda. Las muestras positivas para EV fueron confirmadas y tipificadas por secuenciación. Posteriormente, se utilizó secuenciación de siguiente generación para obtener el genoma viral completo. Resultados: De 1705 muestras, 13 fueron positivas para EV. Los pacientes con EV presentaron la siguiente comorbilidad: enfermedad pulmonar crónica (7.7\%), enfermedad neoplásica (15.4\%), asma/rinitis alérgica (23\%), neumonías de repetición (23\%), y otras (23\%). De las 13 muestras positivas para EV, tres resultaron positivas para EV-D68. Dichos casos requirieron ventilación mecánica invasiva, no tuvieron afectación neurológica y sobrevivieron. Conclusiones: La afectación por EV-D68 de la población estudiada fue menor que lo reportado en México durante el mismo periodo. Los casos de infección por EV-D68 presentan diversa comorbilidad, aunque escasas enfermedades pulmonares, lo cual pudiera explicar la baja tasa de ataque. La presencia del sistema de vigilancia epidemiológica establecido y la prevención de infecciones pudieron haber contenido el brote.
\end{abstract}

Palabras clave: Enterovirus D humano. Neumonía. Epidemiología. Niños.

\section{Surveillance for the identification of cases of acute respiratory infection by enterovirus D68 in children in a tertiary level care hospital during 2014-2016}

\section{Abstract}

Background: The reemergence of enterovirus D68 (EV-D68) infections in the United States was reported from August-October 2014 (691 cases). In Mexico, an outbreak at the National Institute of Respiratory Diseases was reported (24 cases).

Correspondencia:

*Ana Estela Gamiño-Arroyo

E-mail: analetse@ hotmail.com
Disponible en internet: 02-03-2018 Bol Med Hosp Infant Mex. 2018;75:23-30 www.bmhim.com

1665-1146/@ 2018. Hospital Infantil de México Federico Gómez, impreso por Permanyer México SA de CV, todos los derechos reservados. 
The results of epidemiological surveillance of Enterovirus sp. (EV) and other respiratory viruses in a national pediatric tertiary care level hospital are presented. Methods: Following the alert issued by the reemergence of EV-D68 in 2014, epidemiological surveillance - which only detected respiratory viruses by PCR in patients with influenza-like illness using nasopharyngeal swabs - expanded to include children with asthma exacerbation or acute respiratory distress. Positive samples to EV were confirmed and typed by sequencing. Subsequent sequencing was used to obtain the complete viral genome. Results: Of 1705 samples, 13 were positive to EV. Patients with EV presented the following comorbidities: chronic lung disease (7.7\%), neoplastic disease (15.4\%), allergic asthma/rhinitis (23\%), recurrent pneumonia (23\%), and other (23\%). Of the 13 samples positive for EV, three were positive for EV-D68. These cases required invasive mechanical ventilation, presented no neurological involvement and survived. Conclusions: The impact of the population studied by EV-D68 was lower than that reported in Mexico during the same period. Cases of EV-D68 infection had multiple comorbidities, but few pulmonary comorbidities, which could explain the low attack rate. The epidemiological surveillance and infection prevention system may have contained the outbreak.

Key words: Human enterovirus D. Pneumonia. Epidemiology. Pediatrics.

\section{Introducción}

El enterovirus humano D68 (EV-D68) es un miembro de las especies de enterovirus $D$ que pertenece al género Enterovirus y a la familia Picornaviridae. Solo cinco serotipos se han identificado. En 1962 se identificó el rinovirus tipo 87 (HRV87) en pacientes pediátricos hospitalizados con infección respiratoria en California (EE.UU.) ${ }^{1}$. Recientemente, el HRV87 fue reclasificado como EV-D68, considerando los análisis filogenéticos y de neutralización serológica cruzada². Las cepas de EV-D68 se clasifican en tres linajes de acuerdo con la secuencia del gen VP1 ${ }^{1}$. Las cepas de los linajes 1 y 2 forman grupos en la misma región geográfica, mientras que las cepas del linaje 3 no presentan un patrón geográfico de circulación específico. Dichos linajes, descritos por Meijer, et al. ${ }^{3}$, corresponden a los grupos B, C y A, respectivamente, que fueron descritos por Tokarz, et al. ${ }^{4}$ Recientemente se describió el grupo $D^{5}$. El espectro clínico abarca infecciones respiratorias agudas con diversa gravedad, desde enfermedad respiratoria aguda de vías respiratorias altas hasta neumonía grave, siendo esta condición la más frecuente ${ }^{1}$.

En el continente americano se han reportado diversos casos de EV-D68: 17 en Canadá en $2014^{6}$ y 26 en los EE.UU., de 1970 a $2005^{7}$. De agosto a octubre de 2014 se reportó un incremento del número de casos, con un total de 691 en 46 Estados de la unión americana; la mayoría ocurrió en niños con enfermedad respiratoria grave, produciendo casos fatales ${ }^{8,9}$. En México se reportó un brote de 24 casos de infección por EV-D68 en niños hospitalizados por neumonía o exacerbación de asma, que correspondió al 19\% de estos casos con infección respiratoria aguda, con tos y disnea como síntomas predominantes. Además, la infección se asoció con linfocitopenia y propensión al desarrollo de hipoxemia ${ }^{10}$. Debido al incremento de los casos de EV-D68 en todo el mundo ${ }^{3,11-15}$, se le considera como un patógeno reemergente ${ }^{1}$.

El Hospital Infantil de México Federico Gómez (HIMFG) es un hospital de tercer nivel de atención, de referencia nacional. Recibe alrededor de 7,000 pacientes por año provenientes de todos los Estados del país. Aproximadamente el $80 \%$ de los pacientes cursa con algún grado de inmunocompromiso, principalmente debido a diferentes tipos de cáncer.

En el presente artículo se expone el resultado de la vigilancia epidemiológica durante la reemergencia y la alerta para EV-D68 (octubre de 2014 a enero 2016) en el HIMFG, así como la caracterización molecular de la cepa viral. Además, se muestran otros virus respiratorios identificados durante dicho periodo. Los datos derivan del protocolo con registro HIM/2012/031, aprobado por el Comité de Investigación del HIMFG.

\section{Métodos}

\section{Vigilancia epidemiológica}

Desde enero de 2013 se realiza en el HIMFG la vigilancia sistemática para la detección de virus respiratorios en todos los pacientes con datos de infección respiratoria aguda grave o enfermedad tipo influenza), tanto de origen nosocomial como comunitario. Los criterios de inclusión que se consideran para enfermedad tipo influenza son fiebre o historia de fiebre mayor 0 igual a $38^{\circ} \mathrm{C}$, tos y cefalea, acompañadas de uno o más de los siguientes signos o síntomas: rinorrea, coriza, artralgias, mialgias, postración, odinofagia, dolor torácico, dolor abdominal, congestión nasal o diarrea. En los niños menores de 5 años, la irritabilidad, en 
Tabla 1. Iniciadores utilizados en este estudio

\begin{tabular}{|l|l|l|l|l|l|}
\hline Fragmento & Iniciador & Sentido & Secuencia & Posición ${ }^{*}$ & Protocolo \\
\hline 1 & EVD68FwdExt1 & Sentido & AAA ACA GCC TTG GGG TTG & $1-18$ & $\begin{array}{l}\text { RT-PCR/PCR } \\
\text { semianidada }\end{array}$ \\
\hline & EVD68RevExt1 & Antisentido & TCT TAA CTG TAC AAA GGA YCT GGT G & $2700-2676$ & RT-PCR \\
\hline & EVD68RevSN1 & Antisentido & TTT TCA CRG TGT CAG TTG CT & $2428-2409$ & PCR semianidada \\
\hline & EVD68FwdExt2 & Sentido & AGT GGA TCC CAC TAC AGG ATG & $2158-2178$ & $\begin{array}{l}\text { RT-PCR/PCR } \\
\text { semianidada }\end{array}$ \\
\hline & EVD68RevExt2 & Antisentido & TGA TAC AAA GGT GGC AAT GG & $5226-5207$ & RT-PCR \\
\hline & EVD68RevSN2 & Antisentido & GGG CAG CAT CTT TTR TAA TTG G & $4868-4847$ & PCR semianidada \\
\hline \multirow{2}{*}{3} & EVD68FwdExt3 & Sentido & AAG GCT TTG TCA CGC AGA TT & $4723-4742$ & $\begin{array}{l}\text { RT-PCR/PCR } \\
\text { semianidada }\end{array}$ \\
\hline & EVD68RevExt3 & Antisentido & GAA AGT AAC TAY AAC TTG GGT TTC A & $7299-7275$ & RT-PCR \\
\hline & EVD68RevSN3 & Antisentido & TCG TCT AAG ACT AGA GTA TGCA GGT & $7242-7218$ & PCR semianidada \\
\hline
\end{tabular}

${ }^{*}$ Con respecto a la secuencia KM851225.1.

sustitución de la cefalea, se considera como un signo cardinal. En los mayores de 65 años y en los pacientes inmunocomprometidos no se considera la fiebre como un signo cardinal ${ }^{16}$.

Los criterios de inclusión para la infección respiratoria aguda grave son la dificultad al respirar, el antecedente de fiebre mayor o igual a $38{ }^{\circ} \mathrm{C}$ y la tos, con uno o más de los siguientes síntomas: ataque al estado general, dolor torácico o polipnea ${ }^{16}$. A partir de octubre de 2014, derivado de la alerta de emergencia de EV-D68 ${ }^{17}$, se incluyó en la vigilancia la toma de muestra a pacientes con exacerbación aguda por asma o broncoespasmo. Para este estudio se obtuvieron, de manera prospectiva, los datos demográficos y clínicos de los pacientes con EV-D68, por medio de revisión clínica y datos del expediente.

\section{Detección de virus respiratorios por microarreglos de baja densidad}

El diagnóstico de los virus respiratorios se realizó mediante microarreglos de baja densidad, utilizando la plataforma CLART ${ }^{\circledR}$ PneumoVir (GENOMICA), siguiendo las instrucciones del fabricante para la detección de los siguientes virus: adenovirus, bocavirus, coronavirus, enterovirus (echovirus), influenza A (subtipos H3N2 humano, H1N1 humano y H1N1/2009), B y C, metaneumovirus (subtipos $A$ y B), parainfluenza 1, 2, 3 y 4 (subtipos $A$ y $B$ ), rinovirus y virus sincicial respiratorio (VSR) tipos A y B.

\section{Identificación específica y obtención del genoma del EV-D68}

Debido a que la infección por EV puede confirmarse mediante cultivo celular o reacción en cadena de la polimerasa (PCR) específica ${ }^{18}$, se extrajo el RNA viral de las muestras positivas utilizando el QIAamp Viral RNA Mini Kit (Qiagen), siguiendo las recomendaciones del fabricante. La diferenciación de enterovirus/rinovirus mediante PCR en tiempo real (RT-PCR) semianidada con los iniciadores EV1, EV2 y EV3, y la posterior identificación específica de EV-D68 mediante RT-PCR, se realizaron siguiendo los protocolos previamente descritos ${ }^{10}$. Una vez identificadas las muestras positivas para EV-D68, se seleccionó la muestra 2351 obtenida del caso 3 , debido a que presentó un valor de umbral de ciclo (CT) de 26.5 (menor que el de las muestras de los casos 1 y 2) en la prueba diagnóstica de RT-PCR en tiempo real. Esta cifra indica un valor de carga viral adecuado para la amplificación de los fragmentos genómicos mediante la técnica de secuenciación de productos de amplificación, utilizando secuenciación masiva en paralelo.

Para este fin, se diseñaron iniciadores de PCR para la cobertura total del genoma mediante tres reacciones de RT-PCR semianidada (Tabla 1), utilizando el programa Primer 3 Plus $^{19}$ y como blanco la secuencia genómica de la cepa US/MO/14-18947, con número de acceso KM851225 del GenBank. Se utilizó el estuche SuperScript $^{\circledR} \quad$ III Platinum $^{\circledR}$ One-Step qRT-PCR 
(Invitrogen), con las concentraciones de reactivos recomendadas por el fabricante y los iniciadores a una concentración de 30 pmol por reacción. Las condiciones, tanto para la primera como para la segunda ronda de amplificación, fueron 30 minutos a $50^{\circ} \mathrm{C}$ para la retrotranscripción, 2 minutos a $95^{\circ} \mathrm{C}$ para la activación de la Taq polimerasa, seguida de 40 ciclos de 15 segundos a $95^{\circ} \mathrm{C}$ para la desnaturalización, 30 segundos a $53^{\circ} \mathrm{C}$ para el alineamiento de los iniciadores y $4 \mathrm{mi}-$ nutos a $72{ }^{\circ} \mathrm{C}$ para la extensión, además de un paso de extensión final a $72{ }^{\circ} \mathrm{C}$ por 5 minutos. Una vez generados los productos de amplificación, se realizó una mezcla de ellos a una concentración final de $2 \mathrm{ng} / \mu \mathrm{l}$ y se generaron las librerías para la secuenciación utilizando el estuche Nextera XT, de acuerdo con las instrucciones del fabricante. Se realizó la secuenciación en un equipo MiSeq $^{\circledR}$ (Illumina) utilizando 150 ciclos. Al término de la secuenciación se realizó el ensamblaje por mapeo de la secuencia con el software Newbler v. 2.6, utilizando la secuencia de HEVD68ref-NY329 (número de acceso KP745767.1) como referencia. El promedio de la profundidad obtenida fue de 1300X.

\section{Análisis filogenético}

Se realizó el análisis de 98 genomas del EV-D68 disponibles en la base de datos GenBank y obtenidos de aislados de diferentes países donde han ocurrido brotes, utilizando el software MEGA6 ${ }^{20}$, con el método de máxima verosimilitud basado en el modelo de sustitución de Tamura-Nei y distribución gamma.

\section{Resultados}

En el periodo de octubre de 2014 a enero de 2016 se tomaron 1,705 muestras nasofaríngeas, que tuvieron un porcentaje de positividad para cualquier virus respiratorio del $49.85 \%(n=850)$ (Tabla 2), procedentes de pacientes con un rango intercuartil de edad de 2 a 8 años y una mediana de 4 años; y 360 (42.4\%) correspondieron al sexo femenino. El rinovirus fue el virus más prevalente, con el $28.1 \%$ (239 casos), seguido del VSR con el $23.6 \%$ (201 casos) y de coinfecciones en el $17.3 \%$ (147 casos). El porcentaje de las muestras positivas para EV fue del $1.5 \%(n=13)$. De las muestras positivas para $E V$, el $53.8 \%(n=7)$ fueron casos en coinfección: dos con rinovirus y dos con tres virus identificados. La edad de los pacientes infectados con EV fue de 2 a 7 años (media de 3.1 años y mediana de 5 años). Cuatro pacientes (30.7\%) correspondieron al sexo femenino. Presentaban la siguiente comorbilidad:
Tabla 2. Virus detectados en los pacientes analizados

\begin{tabular}{|l|c|}
\hline Virus & $\begin{array}{c}\mathbf{8 5 0} \text { casos } \\
\mathbf{n}(\%)\end{array}$ \\
\hline Adenovirus & $23(2.7)$ \\
Bocavirus & $50(5.8)$ \\
Coronavirus & $1(0.1)$ \\
Enterovirus & $6(7$ en coinfección) $(0.7)$ \\
Influenza & $53(6.2)$ \\
Metaneumovirus & $25(2.9)$ \\
Parainfluenza & $105(12.4)$ \\
Rinovirus & $239(28.1)$ \\
Virus sincitial respiratorio & $201(23.6)$ \\
Coinfecciones* & $147(17.3)$
\end{tabular}

*Excepto con enterovirus.

uno con enfermedad pulmonar crónica $(7.7 \%)$, dos con enfermedad neoplásica (15.4\%), tres con asma/rinitis alérgica (23\%), tres con neumonías de repetición (23\%), tres con otras patologías (23\%) y un paciente sano (7.7\%).

Se detectaron tres casos con PCR positiva para EVD68 (4.3\% de los casos positivos para EV), los cuales no presentaron afectación neurológica. A continuación, se describen los casos.

\section{Caso 1}

Varón de 1 año y 9 meses de edad con desnutrición aguda, antecedente de sibilante temprano y dos hospitalizaciones previas por neumonía adquirida en la comunidad. Madre asmática. Inmunizaciones acordes con el esquema nacional de vacunación, excepto la vacuna contra influenza estacional. Ingresó a urgencias por irritabilidad y dificultad respiratoria, sin fiebre documentada. En la exploración física presentó broncoespasmo, saturación de $\mathrm{O}_{2}$ del $76 \%$ y acidosis respiratoria descompensada; requirió ventilación mecánica por 72 horas. Los resultados de sus exámenes de laboratorio fueron hemoglobina $(\mathrm{Hb}) 12.7 \mathrm{~g} / \mathrm{dll}$, hematocrito (Hto) $38 \%$, leucocitos $8,100 / \mu l$, neutrófilos $80.2 \%$, linfocitos $13.6 \%$ y plaquetas $266,000 / \mu l$. El paciente recibió tratamiento antibiótico con cefotaxima, dicloxacilina y claritromicina por neumonía grave. El día del ingreso se realizó hisopado nasofaríngeo, en el que se identificó EV. Posteriormente se confirmó el EV-D68 mediante secuenciación parcial y RT-PCR.

El aspirado endotraqueal mostró desarrollo de biota habitual y hemocultivos sin desarrollo bacteriano. En la radiografía de tórax se observó infiltrado intersticial difuso bilateral (Fig. 1). Al sexto día de internamiento se dio de alta por mejoría. 


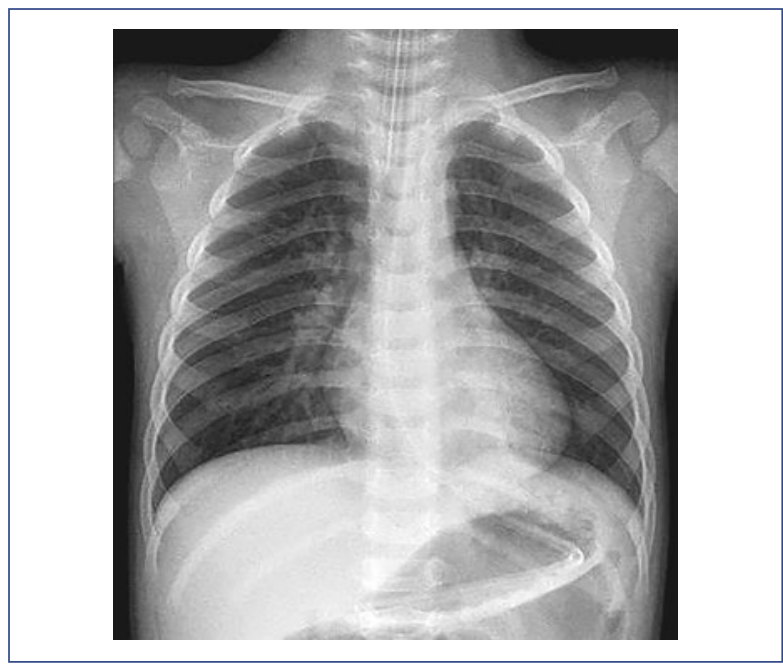

Figura 1. Radiografía de tórax. Se observa un infiltrado intersticial difuso bilateral.

\section{Caso 2}

Varón de 1 año 7 meses de edad, con antecedente de neumonía grave adquirida en la comunidad y taquicardia supraventricular a los 9 meses de edad. Fue valorado por el servicio de cardiología, sin requerir manejo farmacológico. Acudió a urgencias por presentar rinorrea y tos, sin fiebre documentada. A la exploración física se encontró dificultad respiratoria progresiva, saturación de $\mathrm{O}_{2}$ del $67 \%$ e hipotensión (que requirió maniobras de reanimación avanzada); se instauró manejo hídrico y ventilación mecánica. Los resultados de los exámenes de laboratorio fueron los siguientes: Hb $9.6 \mathrm{~g} / \mathrm{dl}$, Hto $29.4 \%$, leucocitos $17,300 / \mu \mathrm{l}$, neutrófilos $80 \%$, linfocitos $16 \%$ y plaquetas $204,000 / \mu$ l. La gasometría arterial resultó con acidosis metabólica (lactato $5.5 \mathrm{mmol} / \mathrm{l}$ ). Recibió tratamiento antibiótico con ampicilina-sulbactam. El día del ingreso se realizó hisopado nasofaríngeo, en el que se identificó EV. Posteriormente se confirmó el EV-D68 mediante secuenciación parcial y RT-PCR. No se identificó coinfección con bacterias (mediante hemocultivos) y no se hallaron otros virus respiratorios. La radiografía de tórax mostró datos de atrapamiento aéreo, horizontalización de los arcos costales, abatimiento de los hemidiafragmas y aumento de trama broncopulmonar (Fig. 2). El tiempo de estancia hospitalaria fue de 7 días.

\section{Caso 3}

Varón de 15 años de edad (cepa 2351) con diagnóstico de linfoma de Hodgkin variedad esclerosis nodular

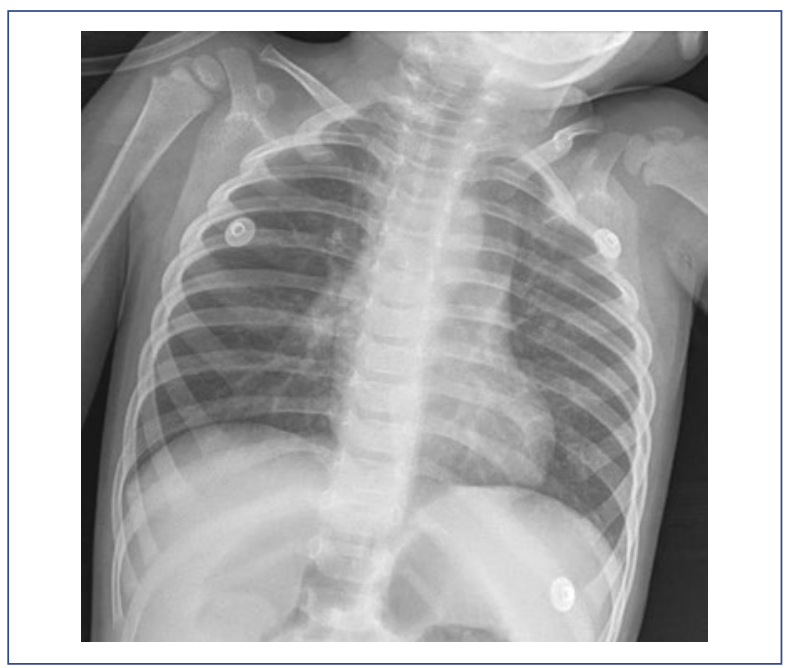

Figura 2. Radiografía de tórax. Se observan datos de atrapamiento aéreo, horizontalización de los arcos costales, abatimiento de los hemidiafragmas y aumento de trama broncopulmonar.

en estadio IIB primario cervical-mediastinal con recaída temprana supradiafragmática e infradiafragmática en el segundo ciclo posrecaída. Recibió un primer ciclo con ifosfamida, vinblastina, citarabina y brentuximab; el segundo ciclo, con vinorelbina, ifosfamida y citarabina. Acudió después por tos y dificultad respiratoria de un día de evolución. En la exploración física se observaron adenopatías submandibulares bilaterales, móviles y no dolorosas, tórax con movimientos de amplexión y amplexación disminuidos, tiros intercostales bajos, retracción xifoidea, campos pulmonares hipoventilados, sibilancias basales y estertores. Su temperatura era de $39{ }^{\circ} \mathrm{C}$, la frecuencia cardiaca de 159 latidos/min, la frecuencia respiratoria de 19/min, la saturación del $88 \%$, la presión arterial de 102/68 mmHg, y los pulsos eran débiles. Los resultados de sus exámenes de laboratorio fueron: $\mathrm{Hb} 14.3 \mathrm{~g} / \mathrm{dl}$, Hto 42\%,

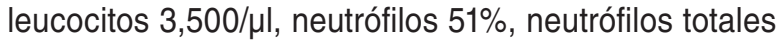
1,785 , linfocitos $20 \%$, monocitos $23 \%$, eosinófilos $5 \%$, basófilos $1 \%$, plaquetas $210,000 / \mu l$, proteína C reactiva $2.48 \mathrm{mg} / \mathrm{dl}$ y procalcitonina $<0.10 \mathrm{ng} / \mathrm{ml}$. Acidosis respiratoria compensada con lactato de $1.1 \mathrm{mmol} / \mathrm{l}$. La radiografía de tórax mostró infiltrado con patrón mixto, difuso bilateral, sin evidencia de consolidación (Fig. 3). A su ingreso se le administraron dos cargas con cristaloides a dosis de $20 \mathrm{ml} / \mathrm{kg}$. El paciente recibió tratamiento con cefepima (7 días) y amikacina (3 días), además de metilprednisolona intravenosa y micronebulizaciones con salbutamol y bromuro de ipratropio. Requirió presión positiva continua en las vías 


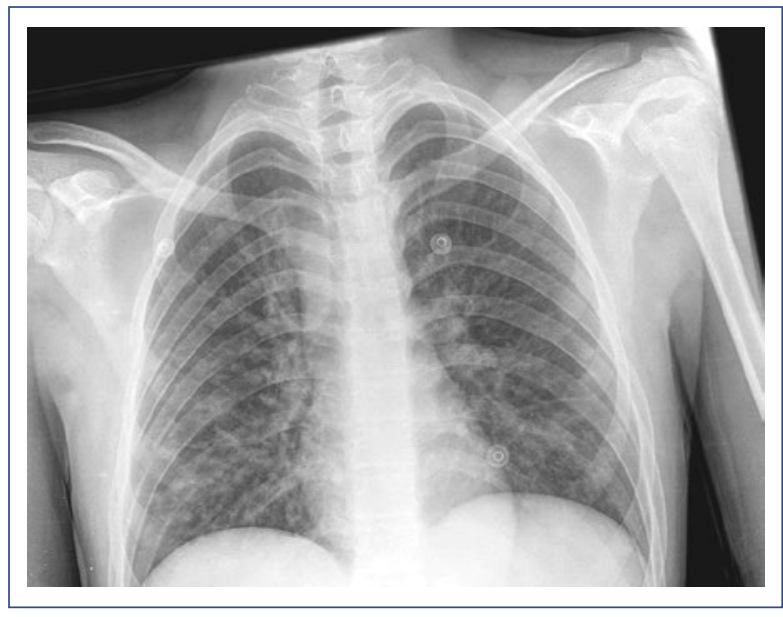

Figura 3. Radiografía de tórax que muestra un infiltrado con patrón mixto, difuso, bilateral, sin evidencia de consolidación.

respiratorias (17 horas); posteriormente, mascarilla facial con reservorio a razón de $10 \mathrm{l} / \mathrm{min}$ y después aporte de $\mathrm{O}_{2}$ con puntas nasales a $1 \mathrm{l} / \mathrm{min}$. Esto permitió lograr una saturación mayor del $90 \%$. El tiempo de estancia hospitalaria fue de 9 días. El diagnóstico fue de neumonía adquirida en la comunidad por EV. El paciente fue dado de alta con puntas nasales a $1 \mathrm{l} / \mathrm{min}$. La secuencia del genoma del EV-D68 obtenido fue incluida en la base de datos GenBank bajo el número KT825142.

\section{Discusión}

El presente estudio constituye el segundo reporte sobre casos infantiles de infección respiratoria aguda causada por EV-D68, en 2014, en México. El Instituto Nacional de Enfermedades Respiratorias (INER) reportó los primeros 24 casos en población pediátrica de un centro de enfermedades respiratorias, con una media de edad de 5.2 años y un $54.2 \%$ de afectación en el sexo femenino ${ }^{10}$.

La media de edad de los casos presentes fue de 6.1 años, con exclusiva afectación de pacientes de sexo masculino. La media de edad en ambos centros concuerda.

En este reporte, los pacientes presentaron un cuadro inicial de tos, rinorrea y disnea, mismo que coincide con lo reportado por el INER ${ }^{10}$. Los pacientes descritos fueron recibidos en el servicio de urgencias con deterioro respiratorio progresivo, hipoxemia y broncoespasmo. En España, se reportó el $58 \%$ de los casos con infección respiratoria aguda causada por EV con hipoxemia ${ }^{13}$.

Los tres pacientes requirieron ingreso a la unidad de cuidados intensivos. Los lactantes no presentaron fiebre, pero en el paciente adolescente sí se documentó fiebre de alto grado. En el INER se reportó fiebre en el $67 \%$ de los casos $^{10}$; en Kansas (EE.UU.), en el $26 \%$, y en Chicago (EE.UU.), en el $18 \%{ }^{21}$. Todos los pacientes del presente reporte requirieron ventilación mecánica, a diferencia de lo publicado por Vázquez-Pérez, et al. ${ }^{10}$, quienes reportaron que solo el 25\% $(n=6)$ lo ameritó. Los pacientes no presentaron afectación neurológica, lo cual concuerda con los casos previamente reportados en México ${ }^{10}$ y Españ ${ }^{13}$, a diferencia de los de EE.UU., donde se ha encontrado una relación de EV-D68 con parálisis flácida, aunque es una manifestación rara ${ }^{22}$. Uno de los casos de este reporte presentó sibilancias; en el INER se reportaron en el $75 \%{ }^{10}$; en Kansas, en el $21 \%^{21}$; y en España se reportaron sibilancias recurrentes en el $83 \%{ }^{13}$. De manera relevante, uno de los casos reportados en este trabajo se identificó como sibilante temprano, antecedente importante en los casos de infección por EV-D68 ${ }^{9}$. En los EE.UU. se reportó una mayor relación con asma, del $68 \%$ y el $73 \%$ en Kansas y Chicago ${ }^{21}$, respectivamente, a diferencia de lo reportado en México, que fue del $37.5 \%{ }^{10}$. En cuanto a los hallazgos radiográficos en este estudio, principalmente se encontraron infiltrado intersticial y datos de atrapamiento aéreo; en Kansas se reportó infiltrado parahiliar y atelectasias ${ }^{21}$, y en el INER se reportó un $62.5 \%$ de los casos con opacidades (neumonía) ${ }^{10}$.

Aunque se llevó a cabo una vigilancia epidemiológica en pacientes hospitalizados para búsqueda de casos de EV-D68 en un hospital de referencia, solo se identificaron tres. El presente reporte no concuerda con lo referido previamente en México, con un reporte de 24 casos en un solo centro en el mismo periodo. Es posible que el menor número de casos identificados en este trabajo, en comparación con el reporte del INER, se deba a que los pacientes que se atienden en el HIMFG no son predominantemente asmáticos o con antecedente de broncoespasmo, sino más bien pacientes inmunocomprometidos y con comorbilidad de otro tipo.

El análisis filogenético mostró que la cepa MEX/ DF/2014-InDRE2351 pertenece al grupo B de clasificación del EV-D68, que incluye la mayoría de las secuencias obtenidas a partir de casos del brote de los EE.UU. en 2014, y se ha propuesto que deriva de la cepa CA/ 




Figura 4. Árbol filogenético basado en genomas completos de EV-D68. El análisis incluyó las cepas de casos en México, las secuencias obtenidas a partir del brote de los EE.UU. en 2014 y cepas representativas de los subtipos A, $B, C$ y la recién descrita $D$. Las secuencias están marcadas con el número de acceso GenBank y la designación de la cepa.

AFP/11-17675 (Fig. 4). La relación evolutiva más cercana fue establecida con la cepa EV-D68/Homo sapiens/ EE.UU./SSENT29/2014, identificada en un paciente pediátrico (mujer, de 5 años de edad) en Massachusetts (EE.UU.), en septiembre de 2014. La secuencia del genoma del EV-D68 obtenido del caso 3 fue incluida en la base de datos GenBank con el número de acceso KT825142.
En 2014 se estableció un riesgo moderado de transmisión del EV-D68 basado en que la circulación del virus en la población es baja, de acuerdo con los estudios realizados en la Unión Europea ${ }^{21}$. Sin embargo, se debe continuar la vigilancia activa para detectar nuevos casos. Por tal motivo, se recomienda el tamizaje para la búsqueda de EV-D68 en los casos negativos para otros virus respiratorios, en aquellos con reporte de EV o rinovirus y en los casos graves de infección respiratoria aguda ${ }^{21}$. Aunque en el HIMFG la vigilancia epidemiológica con toma de hisopado nasofaríngeo en casos con infección respiratoria aguda se realiza desde hace varios años, y se agregó el cuadro de broncoespasmo debido a la alerta sanitaria, no se encontraron más casos que los descritos ni transmisión secundaria. Las medidas aplicadas que pudieron ayudar a evitar la transmisión fueron la estricta aplicación de medidas de aislamiento por contacto y gotas en todo paciente en quien se diagnosticara EV, además de la higiene de manos, la cual, durante el periodo de estudio, se mantuvo en el $72-80 \%^{23}$.

Este estudio sugiere que es posible que el EV-D68 no afecte de manera frecuente a pacientes pediátricos con comorbilidad importante o inmunocompromiso, como son los que se reciben en este centro. En contraste, los pacientes con patología pulmonar previa, como sugieren los Centros de Control de Enfermedades de Europa ${ }^{21}$ y el reporte mexicano de Vázquez-Pérez ${ }^{10}$, pueden afectarse de manera más frecuente. En el estudio de vigilancia realizado en Europa, de julio a diciembre de 2014 y con la participación de 13 países, se reportó un $4.1 \%$ de pacientes con inmunocompromiso de un total de 196 niños menores de 17 años con información documentada. En el grupo de menores de 2 años (con información disponible en el 76\% de los casos) se reportaron problemas respiratorios crónicos/ recurrentes en el $21.9 \%$, otra comorbilidad en el $11 \%$, inmunocompromiso en el $3.3 \%$ y ausencia de comorbilidad identificada en el $63.7 \%{ }^{24}$.

\section{Agradecimientos}

Agradecemos la colaboración de todo el equipo del InDRE para la caracterización molecular de las cepas virales; la participación de personal médico (adscritos y becarios) del Hospital Infantil de México Federico Gómez, quienes apoyaron en el abordaje de los casos; a la Dra. Mariana Sánchez Curiel Loyo por la revisión y la interpretación de las radiografías de los pacientes; y al equipo de laboratorio clínico por el procesamiento inicial y el resguardo de las cepas virales. 


\section{Responsabilidades éticas}

Protección de personas y animales. Los autores declaran que para esta investigación no se han realizado experimentos en seres humanos ni en animales.

Confidencialidad de los datos. Los autores declaran que han seguido los protocolos de su centro de trabajo sobre la publicación de datos de pacientes.

Derecho a la privacidad y consentimiento informado. Los autores declaran que en este artículo no aparecen datos de pacientes.

\section{Financiamiento}

Fondos federales.

\section{Conflicto de intereses}

Los autores declaran no tener ningún conflicto de intereses.

\section{Bibliografía}

1. Tadatsugu I, Oshitani H. Global reemergence of enterovirus D68 as an important pathogen for acute respiratory infections. Rev Med Virol. 2015:25:102-14.

2. Blomqvist S, Savolainen C, Roman L, Roivainen M, Hovi T. Human rhinovirus 87 and enterovirus 68 represent a unique serotype with rhinovirus and enterovirus features. J Clin Microbiol. 2002;40:4218-23.

3. Meijer A, Van Der Sanden S, Snijders BEP, et al. Emergence and epidemic occurrence of enterovirus 68 respiratory infections in The Netherlands in 2010. Virology. 2012;423:49-57. Disponible en: http://dx.doi.or$\mathrm{g} / 10.1016 /$ i.virol.2011.11.021

4. Tokarz R, Firth C, Madhi SA, et al. Worldwide emergence of multiple clades of enterovirus 68. J Gen Virol. 2012;93:1952-8.

5. Du J, Zheng B, Zheng W, et al. Analysis of enterovirus 68 strains from the 2014 North American outbreak reveals a new clade, indicating viral evolution. PLoS One. 2015;10:1-13.

6. Skowronski DM, Chambers C, Sabaiduc S, et al. Systematic community-and hospital-based surveillance for enterovirus-D68 in three Canadian provinces, August to December 2014. Euro Surveill. 2015;20.

7. Khetsuriani N, Lamonte-Fowlkes A, Oberst S, et al. Enterovirus surveillance - United States, 1970-2005. MMWR Surveill Summ. 2006;55:1-20. Disponible en: http://www.ncbi.nlm.nih.gov/pubmed/16971890
8. Kreuter JD, Barnes A, McCarthy JE, et al. A fatal central nervous system enterovirus 68 infection. Arch Pathol Lab Med. 2011;135:793-6.

9. Midgley CM, Jackson MA, Selvarangan R, et al. Severe respiratory illness associated with enterovirus D68 - Missouri and Illinois. MMWR Morb Mortal Wkly Rep. 2014;63:798-9.

10. Vázquez-Pérez JA, Ramírez-González JE, Moreno-Valencia Y, et al. EV-D68 infection in children with asthma exacerbation and pneumonia in Mexico City during 2014 autumn. Influenza Other Respir Viruses. 2016;10:154-60. Disponible en: http://doi.wiley.com/10.1111/irv.12384

11. Ikeda $T$, Mizuta $K$, Abiko $C$, et al. Acute respiratory infections due to enterovirus 68 in Yamagata, Japan between 2005 and 2010. Microbiol Immunol. 2012;56:139-43.

12. Imamura $T$, Fuji $N$, Suzuki $A$, et al. Enterovirus 68 among children with severe acute respiratory infection, the Philippines. Emerg Infect Dis. 2011;17:1430-5.

13. Calvo C, Cuevas MT, Pozo F, et al. Respiratory infections by enterovirus D68 in outpatients and inpatients Spanish children. Pediatr Infect Dis J. 2016;35:45-9. Disponible en: http://www.ncbi.nlm.nih.gov/pub$\mathrm{med} / 26741582$

14. Xiao $Q$, Ren $L$, Zheng S, et al. Prevalence and molecular characterizations of enterovirus D68 among children with acute respiratory infection in China between 2012 and 2014. Sci Rep. 2015;5:16639. Disponible en: http://www.nature.com/articles/srep16639

15. European Centre for Disease Prevention and Control. An agency of the European Union; 2017. Disponible en: https://ecdc.europa.eu/en/infectious-diseases-public-health/surveillance-and-disease-data/eu-case-definitions

16. Secretaría de Salud de México. Manual para la vigilancia epidemiología de influenza en México. 2014. Disponible en: http://www.ssm.gob.mx/ portal/page/influenza/LINEAMIENTOSDEINFLUENZA.pdf

17. CONAVE. Aviso epidemiológico. Comisión Nacional para la Vigilancia Epidemiológica; 2014. Disponible en: http://www.ssm.gob.mx/portal/ page/vig_epid/2/Aviso Epidemiologico Enterovirus D68-06 octubre 2014. pdf

18. Oermann CM, Schuster JE, Conners GP, et al. Enterovirus D68: a focused review and clinical highlights from the 2014 U.S. outbreak. Ann Am Thorac Soc. 2015;12:775-81.

19. Rozen S, Skaletsky H. Primer3 on the WWW for general users and for biologist programmers. En: Krawetz S, Misener S, editores. Bioinformatics methods and protocols. Totowa, NJ: Humana Press; 2000. p. 365-86.

20. Tamura K, Stecher G, Peterson D, et al. MEGA6 : Molecular Evolutionary Genetics Analysis Version 6.0. Mol Biol Evol. 2013;30:2725-9.

21. European Centre for Disease Control. Enterovirus 68 detections in the USA and Canada. 2014. Disponible en: http://ecdc.europa.eu/en/publications/Publications/enterovirus-68-USA-Canada-rapid-risk-assessment.pdf

22. Greninger AL, Naccache SN, Messacar K, et al. A novel outbreak enterovirus D68 strain associated with acute flaccid myelitis cases in the USA (2012-14): a retrospective cohort study. Lancet Infect Dis. 2015; 15:671-82.

23. de la Rosa-Zamboni D, Xicoténcatl-Cortés J, Cervantes-Castillo A, et al. Hand hygiene program: "Go for 100*". Whole impact (hospital cost, MRSA attack, nosocomial infections and device related infections). Int $J$ Infect Dis. 2016;45:346-7. Disponible en: http://linkinghub.elsevier.com/ retrieve/pii/S1201971216307263

24. Poelman R, Schuffenecker I, Van Leer-Buter C, et al. European surveillance for enterovirus D68 during the emerging North-American outbreak in 2014. J Clin Virol. 2015;71:1-9. 